\title{
Hydro-mechanical behaviour of a pellets based bentonite seal: Numerical modelling of lab scale experiments
}

\author{
Liliana Gramegna ${ }^{1, *}$, Frédéric Collin ${ }^{1}$, Jean Talandier $^{2}$, Christophe Imbert $^{3}$, Robert Charlier $^{1}$ \\ ${ }^{1}$ Université de Liège, Département ArGEnCo - Géotechnique, Géomécanique et Géologie de l'Ingénieur - 4000, Liège 1, Belgique
${ }^{2}$ ANDRA - Agence Nationale pour la gestion des Déchets Radioactifs - 92298, Châtenay-Malabry, France
${ }^{3}$ CEA - Commissariat à l'énergie atomique et aux énergies alternatives - 91191, Gif sur Yvette, France
}

\begin{abstract}
In most of the concept designs for nuclear waste disposals, bentonite-based materials are used to seal underground galleries and shafts. In order to assess the safety of such engineered barriers and to provide a good prediction for the material behaviour, a number of experimental campaigns and constitutive models have been developed mainly focusing on bentonite compacted blocks. On the other hand, in recent years, the use of high density bentonite pellets combined with powdered bentonite has also been considered as an interesting alternative. The bentonite pellets mixtures present a prominent initial heterogeneity level as a result of the inter-pellets porosity, which evolves strongly during hydration. This paper aims to present the numerical modelling strategy adopted for a swelling pressure test on pellets mixture carried by CEA (France). Taking advantage of the finite element code LAGAMINE, the Barcelona Basic model is considered for the bentonite mechanical behaviour and the double porosity model proposed by [1] is used for the water retention behaviour and permeability evolution. Given the already-known complexity of the multiphysical and multiscale coupled processes taking place during bentonite-hydration, the obtained numerical results are in good agreement with experimental measurements. Especially, the non-monotonic evolution of the swelling pressure during the hydration phase is well captured by this model, which is always a challenge for this type of problem.
\end{abstract}

\section{Introduction}

In the context of nuclear waste disposals, most of the experimental studies and constitutive models have mainly focused on bentonite compacted blocks [2] [3]. Nonetheless, the use of high density bentonite pellets combined with powdered bentonite has also been taken into account [4]. This kind of mixture represents an interesting option for the filling of the large volumes involved in the underground galleries and boreholes, being less expensive and technically more efficient with respect to compacted blocks. The bentonite pellets mixtures are characterized by an initial heterogeneous distribution of dry density, which evolves toward a full homogenised structure during hydration [5] [6] [7]. This characteristic affects unquestionably the development of the swelling capacities as well as the water transfer mechanisms of the medium [8].

In this paper, an experimental test investigating the hydro-mechanical properties of a MX-80 pellets mixture is presented [5]. This test gives good indications concerning the material characterisation, which is not as exhaustive as the one available for bentonite compacted blocks. Then, the adopted modelling strategy is described: the Barcelona Basic model is considered for the bentonite mechanical behaviour, pressure dependence is taken into account for some mechanical parameters and the double porosity model proposed by [1] is used for the water retention behaviour and water permeability evolution.
Despite the heterogeneous initial state of the material is well-recognized, in the adopted numerical strategy the overall assembly is considered homogeneous. The selected numerical approach provides results, which compare remarkably well with experimental measurements. Especially, the nonmonotonic evolution of the swelling pressure during the hydration phase and the water-intake evolution are in good agreement with the experimental outcomes.

\section{Materials and method}

This test has been developed by the CEA laboratory. The objective of the test is to investigate the behaviour of MX-80 pellets mixture during water saturation in isochoric conditions [9]. The considered mixture is composed of MX-80 $32 \mathrm{~mm}$ pellets and crushed pellets (MX-80 bentonite: Laviosa-MPC Expangel SP32) arranged layer by layer in a multi-sensor cell not exceeding the target dry density of $1.52 \mathrm{Mg} / \mathrm{m}^{3}$. The dry density for one pellet is between 2.01 and $2.05 \mathrm{Mg} / \mathrm{m}^{3}$, whereas crushed pellets present a particle size between 0 and $2.5 \mathrm{~mm}$. The experimental device (Figure 1) consists of a $240 \mathrm{~mm}$-diameter-oedometric cell fixed base and a mobile piston made of 304L stainless steel. The set is inserted in a clamping frame. A force sensor interposed between the piston and the upper flange measures the swelling pressure transmitted by the piston. A water tank placed $1 \mathrm{~m}$ above the base on a continuous weighing device, allows hydration with a slight differential pressure (about $10 \mathrm{kPa}$ ). Water is 
provided from the base and uniformly distributed on the face of the sample thanks to a stainless-steel porous disk. The upper piston circuit remains open so that the air occluded in the sample can escape. The device is equipped with four radial pressure sensors and five relative humidity/temperature sensors at 20, 40, 60, 80 and $100 \mathrm{~mm}$ from the bottom face. The initial characteristics of the sample are recalled in Table 1.

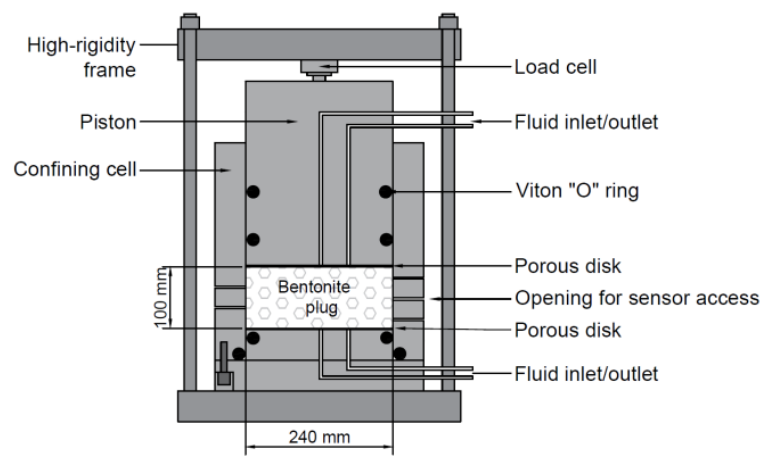

Fig. 1: Schematic representation of the experimental set-up.

Table 1: Initial characteristics of the sample.

\begin{tabular}{|c|c|}
\hline Diameter [mm] & 240 \\
\hline Surface $\left[\mathrm{cm}^{2}\right]$ & 452.389 \\
\hline Height after adjustment [mm] & 105.15 \\
\hline Volume after adjustment $\left[\mathrm{cm}^{3}\right]$ & 4756.8 \\
\hline pellets [\% mass] & 69.885 \\
\hline crushed pellets [\% mass] & 30.115 \\
\hline Clay density [Mg/m $\left.{ }^{3}\right]$ & 2.78 \\
\hline Total porosity [\%] & 45.3 \\
\hline Pore volume [cm $\left.{ }^{3}\right]$ & 2154.8 \\
\hline Water content $[\%]$ & 4.23 \\
\hline Saturation $[\%]$ & 14.19 \\
\hline Apparent density $\left[\mathrm{Mg} / \mathrm{m}^{3}\right]$ & 1.584 \\
\hline Dry density $\left[\mathrm{Mg} / \mathrm{m}^{3}\right]$ & 1.520 \\
\hline
\end{tabular}

\section{Experimental results}

According to [8] the development of the swelling pressure in pellets/powder mixtures shows three phases: a first one with a quick swelling pressure increase, a second one with either a quasi-constant level or even a decrease of the swelling pressure, and the last one with a new increase of the swelling pressure. The interaction between micro and macrostructure accounts for this pattern. The pattern described by [8] is well reproduced by the obtained experimental results (Figure 2). However, it is important to mention that, during an experimental test, the radial pressure measurements are more difficult to evaluate with respect to the axial ones due to the fact that they are strongly affected by the test conditions and representative only of a limited portion of the sample. Consequentially, they have to be treated and interpreted with caution.

The test was stopped at 1214 days after the beginning of hydration. All pressure measurements were stable since approximately the age of 600 days.

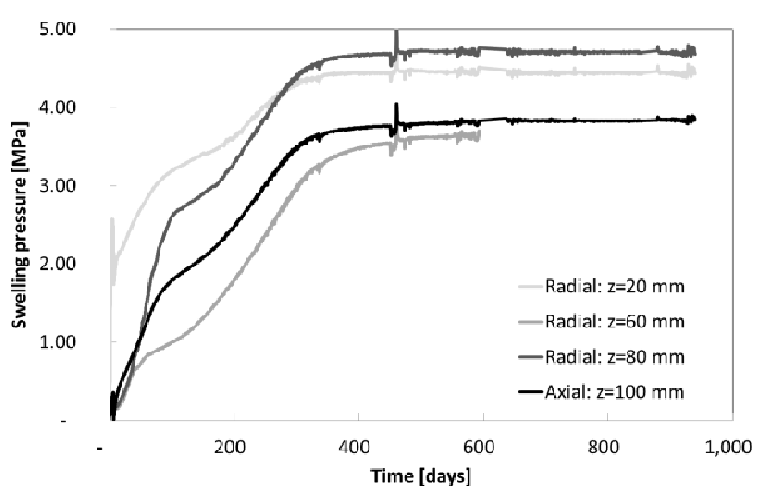

Fig. 2: Swelling pressure in radial and axial directions function of time.

It is worth noting that the swelling pressure stabilization is not consistent with the suction measurement, which reaches the zero constant value since the age of 200 days (Figure 3). Alternatively the swelling pressure development is more coherent with the water intake evolution (Figure 4). Due to this, one can conclude that the RH measurements are not representative of the overall bentonite sample but only of the inter-layer crushed-pellets medium. Thus, these measurements are local, in the same way as the radial pressure measurements, whereas the axial pressure and the water intake are global values.

Consequentially, in this specific case, it can be assumed that the crushed pellets component, thanks to its low dry density (i.e. high void ratio), represents a preferential pathway for water transfer during the first phases of hydration. This feature results in a high initial permeability, which immediately decreases as the pellets swelling and the micro-structure evolution proceed upon wetting.

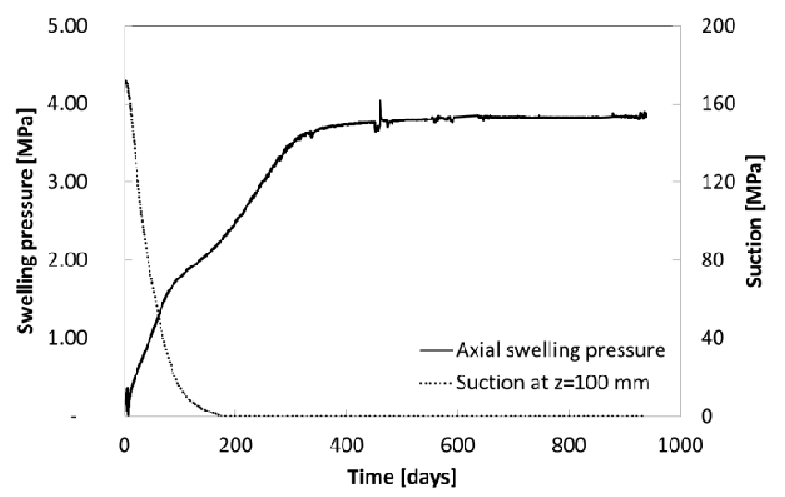

Fig. 3: Swelling pressure in axial direction and suction measurement at $\mathrm{z}=100 \mathrm{~mm}$ from the bottom face function of time. 


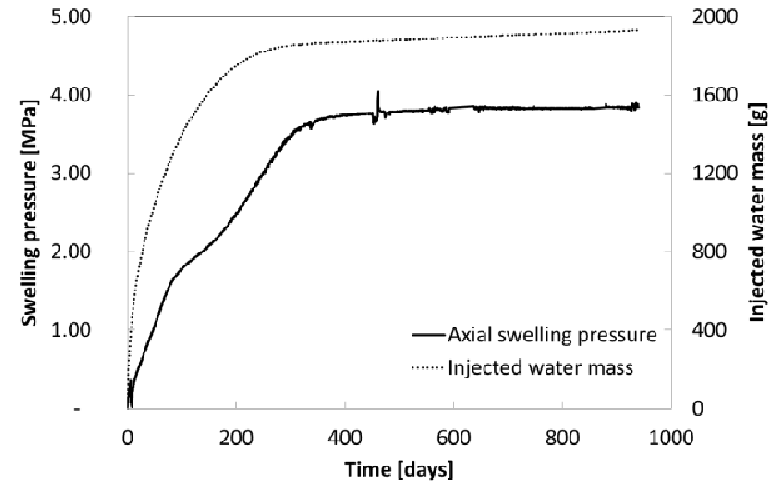

Fig. 4: Swelling pressure in axial direction and water intake function of time.

\section{Coupled hydro-mechanical model}

\subsection{Mechanical model}

The complexity of the coupled multiphysical and multiscale phenomena taking place during bentonite hydration is well known. The Barcelona Basic Model (BBM) [10] is able to reproduce a wide range of phenomena occurring in unsaturated soils and, due to this, it is selected as mechanical constitutive model. The model is formulated adopting net stress $\sigma$ (Eq. 1) and suction $\mathrm{s}$ as stress variables.

$$
\boldsymbol{\sigma}=\boldsymbol{\sigma}_{T}-u_{a} \boldsymbol{I}
$$

With $\sigma \mathrm{T}$ the total stress tensor, ua the air pressure for $\mathrm{s}>0$ and $\mathrm{I}$ the identity tensor.

According to the BBM, under isotropic stress conditions, the variation of volumetric elastic strain is associated to changes in mean net stress $\mathrm{p}$ and suction $\mathrm{s}$ (Eq. 2). Moreover, in order to tackle the stress dependence of the swelling strain for change in suction underlined by [11], Eq. 3 is adopted.

$$
\begin{gathered}
d \varepsilon_{v}^{e}=\frac{\kappa}{1+e} \frac{d p}{p}+\frac{\kappa_{s}}{1+e} \frac{d s}{s+u_{a t m}} \\
\kappa_{s}(p)=\kappa_{s 0} * \exp \left(-\alpha_{p} * p\right)
\end{gathered}
$$

The evolution of the preconsolidation pressure $p_{0}(s)$ is modelled consistently with the concept of increasing the elastic domain with increasing suction (Eq. 4) as well as the rate of increase of the soil stiffness with suction (Eq. 5).

$$
\begin{gathered}
p_{0}(s)=p_{c}\left(\frac{p_{0}^{*}}{p_{c}}\right)^{\frac{\lambda(0)-\kappa}{\lambda(s)-\kappa}} \\
\lambda(s)=\lambda(0)[(1-r) \exp (-\omega s)+r]
\end{gathered}
$$

\subsection{Hydraulic model}

The selected water retention model [1] is formulated in terms of water ratio $e_{w}$ (Eq. 6), which is expressed as the superposition of a contribution from the water stored in the micropores $e_{w m}$ and a second contribution from the water contained in the macropores $e_{w M}$ (Eq. 7)

$$
\begin{gathered}
e_{w}=S_{r} e \\
e_{w}=e_{w m}+e_{w M}
\end{gathered}
$$

The model also considers the microstructure evolution occurring during saturation [12] (Eq. 8).

$$
e_{m}=e_{m 0}+\beta_{0} e_{w}+\beta_{1} e_{w}^{2}
$$

Therefore, global degree of saturation is obtained by the sum of the microstructural and macrostructural degrees of saturation, weighed by the corresponding volumetric fractions (Eq. 9).

$$
S_{r}=\frac{e_{w}}{e}=\frac{e_{m}}{e} S_{r m}+\frac{e_{M}}{e} S_{r M}
$$

Dubinin's isotherm is adopted to describe the water retention behaviour of the microstructure, which is mainly stored by absorption (Eq. 10). For the macrostructural water retention domain, the van Genuchten equation is selected (Eq. 11) replacing the void ratio $e$ by macrostructural void ratio $e_{M}=e-e_{m}$. The parameter $\alpha$ is assumed to depend on the macrostructural void ratio representing the influence of the bentonite structure on the air-entry value (Eq. 12).

$$
\begin{gathered}
e_{w m}\left(s, e_{m}\right)=\mathrm{e}_{m} \exp \left[-\left(C_{a d s} s\right)^{\left.n_{a d s}\right]}\right. \\
e_{w M}(s, e)=\left(e-e_{m}\right)\left[1+\left(\frac{s}{\alpha}\right)^{n}\right]^{-m} \\
\alpha=\frac{A}{e-e_{m}}
\end{gathered}
$$

Finally, in order to consider the double structure nature of compacted bentonite-based materials also in the water transfer mechanisms, the water permeability evolution is modelled considering an Extended KozenyCarman model (Eq. 13) similar to [13], in which the total porosity is substituted by the macrovoid ratio $e_{M}$.

$$
\begin{aligned}
& K_{w} \\
& =K_{w 0} \frac{e_{M}^{\text {expn }}}{\left(1-e_{M}\right)^{\text {expm }}} \frac{\left(1-e_{M 0}\right)^{\text {expm }}}{e_{M 0} \text { expn }}
\end{aligned}
$$

\section{Numerical results and analysis}

\subsection{Geometric configuration of the simulation}

The numerical bentonite sample consists of 25 eightnoded isoparametric elements. The problem is assumed monodimensional and oedometer conditions are considered (Figure 5). The strong heterogeneity of the material is well-recognized, but for sake of simplicity, in this modelling strategy, the sample is considered homogeneous. Thus, same hydro-mechanical properties and hydro-mechanical state are set in the entire domain with initial uniform dry density $\rho_{d}=1.52 \mathrm{Mg} / \mathrm{m}^{3}$ and suction $s=171 \mathrm{MPa}$ (corresponding to the saturation degree $\left.S_{r}=15 \%\right)$. The hydration of the sample is provided from the bottom face (red line, Figure 5) assuming a suction decrease from $171 \mathrm{MPa}\left(p_{w=}-171\right.$ $\mathrm{MPa})$ to $-0.010 \mathrm{MPa}\left(p_{w}=0.010 \mathrm{MPa}\right)$ occurring in 1000 seconds. The sample is subjected to an initial confining stress value of $0.02 \mathrm{MPa}$ in the axial direction and 0.2 
$\mathrm{MPa}$ in the radial one. The mechanical and the hydraulic parameters for the water retention behaviour (Tables 2 and 3 respectively) were derived by the experimental campaign performed by [4] on a similar assembly of MX80 pellets mixture. The parameters for the water permeability evolution were obtained thanks to an iterative procedure in order to reproduce the target results (Table 4).

Table 2: Parameters of the mechanical model.

\begin{tabular}{|c|c|c|c|}
\hline $\boldsymbol{\kappa}$ & {$[-]$} & $\begin{array}{c}\text { Elastic compressibility } \\
\text { coefficient for changes in } \\
\text { mean net stress }\end{array}$ & 0.06 \\
\hline $\boldsymbol{\kappa}_{\boldsymbol{s}}$ & {$[-]$} & $\begin{array}{c}\text { Elastic compressibility } \\
\text { coefficient for changes in } \\
\text { suction }\end{array}$ & 0.07 \\
\hline $\boldsymbol{\alpha}_{\boldsymbol{p}}$ & {$[-]$} & $\begin{array}{c}\text { Parameter controlling the } \\
\text { stress dependency of the } \\
\text { swelling strain for change in } \\
\text { suction }\end{array}$ & $2.6 \times 10^{-7}$ \\
\hline $\boldsymbol{p}_{\boldsymbol{0}}^{*}$ & {$[\mathrm{MPa}]$} & $\begin{array}{c}\text { Preconsolidation pressure for } \\
\text { saturated state }\end{array}$ & 1.86 \\
\hline $\boldsymbol{p}_{\boldsymbol{c}}$ & {$[\mathrm{MPa}]$} & $\begin{array}{c}\text { Reference pressure } \\
\text { controlling the shape of the } \\
\text { LC curve }\end{array}$ & 0.93 \\
\hline $\boldsymbol{\lambda}(\boldsymbol{0})$ & {$[-]$} & $\begin{array}{c}\text { Slope of the saturated virgin } \\
\text { consolidation line }\end{array}$ & 0.2 \\
\hline $\boldsymbol{r}$ & {$[-]$} & $\begin{array}{c}\text { Parameter defining the } \\
\text { minimum soil } \\
\text { compressibility }\end{array}$ & 0.75 \\
\hline $\boldsymbol{\omega}$ & {$[-]$} & $\begin{array}{c}\text { Parameter controlling the } \\
\text { soil stiffness }\end{array}$ & $1.00 \mathrm{E}-07$ \\
\hline
\end{tabular}

Table 3: Parameters of the water retention curve model.

\begin{tabular}{|c|c|c|c|}
\hline$e_{m 0}$ & {$[-]$} & $\begin{array}{l}\text { Microstructural void ratio } \\
\text { for the dry material }\end{array}$ & 0.31 \\
\hline $\boldsymbol{\beta}_{0}$ & {$[-]$} & \multirow{2}{*}{$\begin{array}{l}\text { Parameters quantifying the } \\
\text { swelling potential of the } \\
\text { aggregates }\end{array}$} & 0.1 \\
\hline$\beta_{1}$ & {$[-]$} & & 0.38 \\
\hline$C_{a d s}$ & {$\left[\mathrm{MPa}^{-1}\right]$} & $\begin{array}{l}\text { Parameter associated to the } \\
\text { desaturation rate of the soil }\end{array}$ & 0.0075 \\
\hline$n_{\text {ads }}$ & {$[-]$} & $\begin{array}{l}\text { Parameter controlling the } \\
\text { WRC curvature in the high } \\
\text { suction range }\end{array}$ & 0.2 \\
\hline$n$ & {$[-]$} & \multirow{2}{*}{ Material parameters } & 3 \\
\hline$m$ & {$[-]$} & & 0.45 \\
\hline$A$ & {$[\mathrm{MPa}]$} & $\begin{array}{l}\text { Parameter controlling the } \\
\text { dependence of the air-entry } \\
\text { pressure on the } \\
\text { macrostructural void ratio }\end{array}$ & 0.2 \\
\hline
\end{tabular}

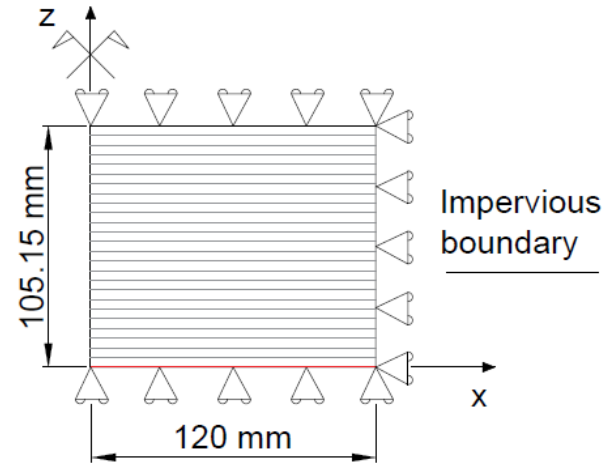

Fig. 5: Boundary condition of the model.

Table 4: Parameters of the permeability evolution model.

\begin{tabular}{|c|c|c|c|}
\hline $\boldsymbol{K}_{\boldsymbol{w} \boldsymbol{0}}$ & {$\left[\mathrm{m}^{2}\right]$} & Reference permeability & $2.48 \times 10^{-20}$ \\
\hline $\boldsymbol{e}_{\boldsymbol{M} \boldsymbol{0}}$ & {$[-]$} & $\begin{array}{c}\text { Reference macroscopic void } \\
\text { ratio }\end{array}$ & 0.31 \\
\hline expm & {$[-]$} & Model parameters & 1.5 \\
\cline { 1 - 1 } $\boldsymbol{\text { expn }}$ & {$[-]$} & & 0.2 \\
\hline
\end{tabular}

\subsection{Permeability evolution and water intake}

The selected law for the permeability evolution allows modelling the high initial permeability related to the crushed-pellets component and its decrease due microstructure evolution and pellets swelling upon water saturation. Starting from a uniform value of intrinsic permeability $K_{w}=4.4 \times 10^{-20} \mathrm{~m}^{2}$, obtained according to Eq. 13 and depending on the saturation degree via $e_{M}$ (Eq. 8 and 11), as the water front proceeds from the bottom face, the permeability of the sample decreases reaching a-quasi-uniform value $K_{w}=1.30 \times 10^{-20} \mathrm{~m}^{2}$ when fully saturated (Figure 6). As observed in Figure 7, the model prediction compares remarkably well with the experimental curve of the water intake. The numerical injected water mass reaches $1854 \mathrm{~g}$ at the end of the simulation, which is comparable with the final value measured during the test (1958 g).

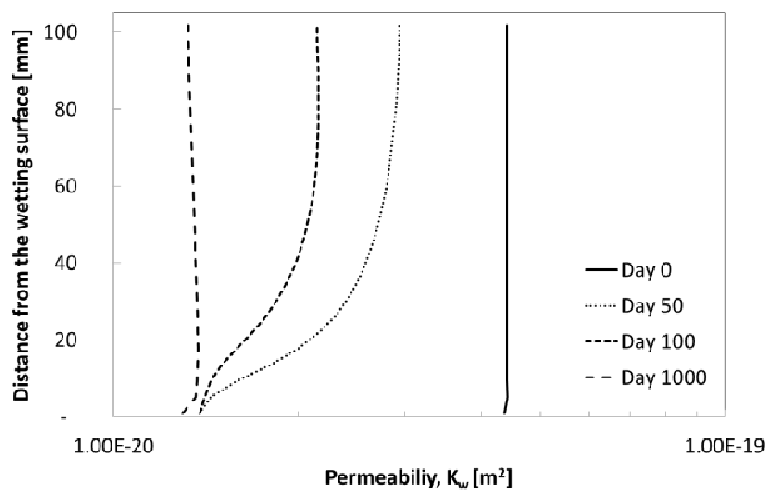

Fig. 6: Evolution through time of permeability over the height of the sample during water injection (numerical results). 


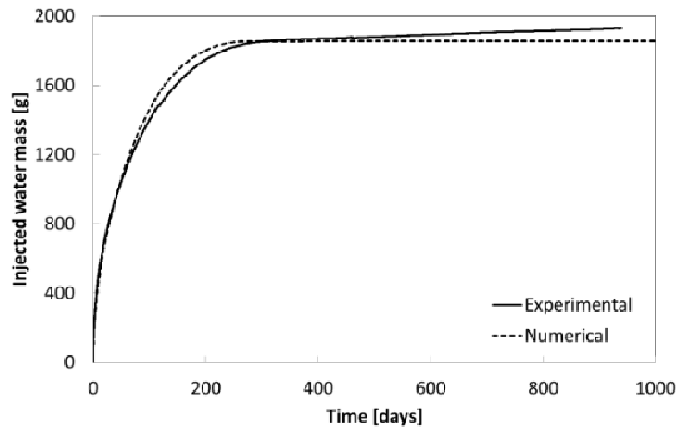

Fig. 7: Water mass injected from the bottom end. Comparison between experimental data and model predictions.

\subsection{Swelling pressure}

As the comparison in Figure 8 shows, the agreement between the experimental and the numerical results for the axial pressure is remarkably good. The trend of the transient phase is well reproduced as well as the stabilization time of the swelling pressure. For the radial stress measurements (Figure 9), the numerical results are in general lower than the experimental ones apart for the measurement at $\mathrm{z}=60 \mathrm{~mm}$ from the wetting surface. The unexpected value at $\mathrm{z}=60 \mathrm{~mm}$ in the experiment is probably due to test conditions or pressure sensor failure. However, the non-monotonic evolution of the swelling pressure during the hydration phase is well captured by this model. The experimental and numerical final values of the swelling pressures are reported in Table 5.

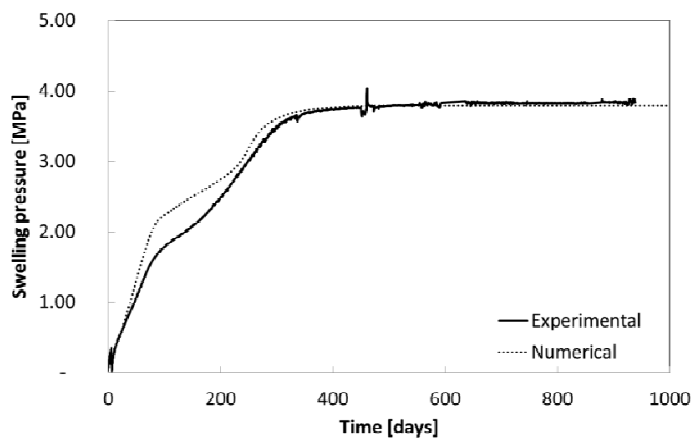

Fig. 8: Swelling pressure in axial direction. Comparison between experimental data and model predictions.

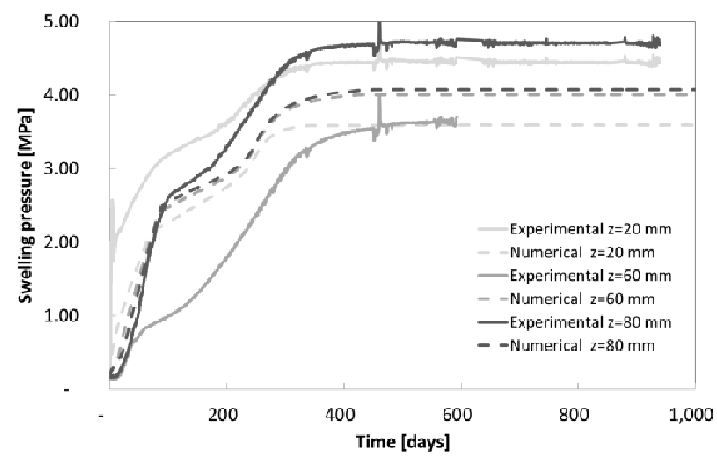

Fig. 9: Swelling pressures in radial direction. Comparison between experimental data and model predictions.
Table 5: Final values of swelling pressure. Comparison between experimental data and model prediction.

\begin{tabular}{|c|c|c|c|c|}
\hline & $\begin{array}{c}\text { Radial, } \\
\mathrm{z}=20 \mathrm{~mm}\end{array}$ & $\begin{array}{c}\text { Radial, } \\
\mathrm{z}=60 \mathrm{~mm}\end{array}$ & $\begin{array}{c}\text { Radial, } \\
\mathrm{z}=80 \mathrm{~mm}\end{array}$ & $\begin{array}{c}\text { Axial, } \\
\mathrm{z}=100 \mathrm{~mm}\end{array}$ \\
\hline & {$[\mathrm{MPa}]$} & {$[\mathrm{MPa}]$} & {$[\mathrm{MPa}]$} & {$[\mathrm{MPa}]$} \\
\hline Experimental & 4.43 & 3,74 & 4,69 & 3,84 \\
\hline Numerical & 3.59 & 4.00 & 4.07 & 3.79 \\
\hline
\end{tabular}

\subsection{Post mortem analysis}

Dry density and water content comparisons of experimental measurements at dismantling and numerical results are presented (Figures 10 and 11). The final experimental and numerical states show similar qualitative features: a vertical density gradient is observed in the direction of hydration, inversely correlated with water content. In addition, Mercury Intrusion Porosimetry (MIP) measurements were performed on freeze-dryed samples taken from the test. Accordingly to [14], pores presenting diameter $\mathrm{d}>300$ $\mathrm{nm}$ are denoted as "macropores". The numerical results present the same order of magnitude of the experimental interpretation (Figure 12).

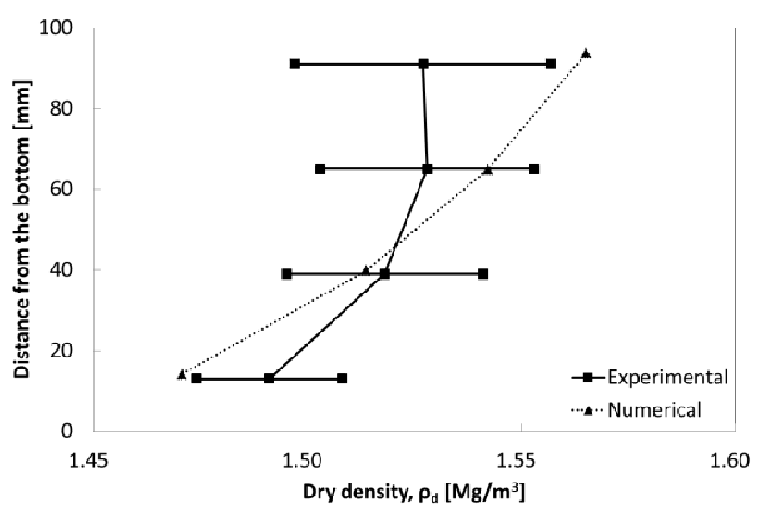

Fig. 10: Dry density distribution over the height of the sample at the end of the test. Comparison between experimental data and model predictions.

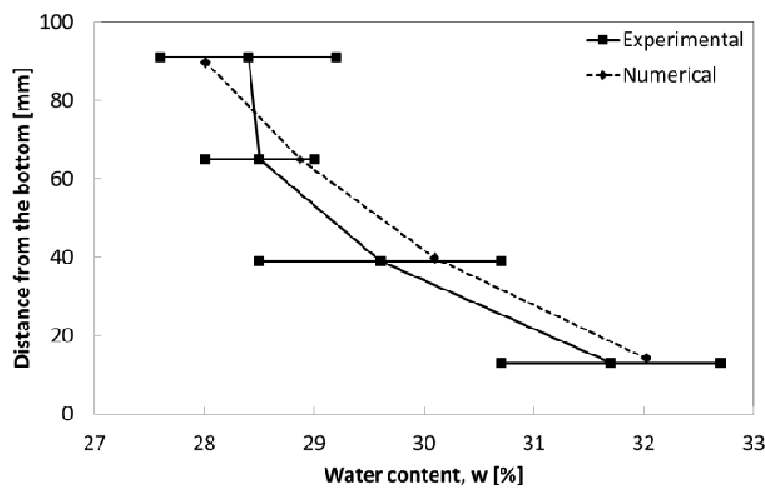

Fig. 11: Water content distribution over the height of the sample at the end of the test. Comparison between experimental data and model predictions. 


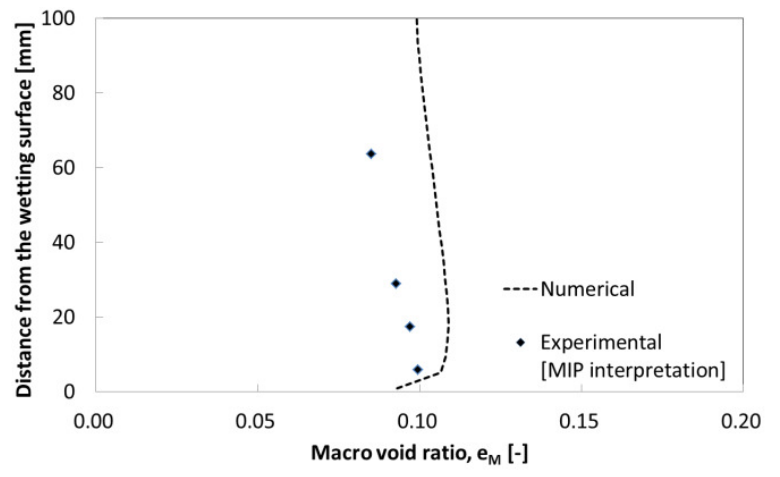

Fig. 12: Macrovoid ratio distribution over the height of the sample at the end of the test. Comparison between experimental data and model predictions.

\section{Conclusions}

This paper showed the experimental isochoric-wetting test performed on a MX80 pellets mixture. Pellets mixtures present a prominent initial heterogeneous dry density distribution, which evolves toward an homogenised structure. This feature affects undeniably the swelling pressure development and water transfer mechanism. Although the proposed numerical approach does not take into account this initial heterogeneous state, the numerical results underline a good agreement with experimental measurements. Especially, the nonmonotonic evolution of the swelling pressure is well captured together with the water intake, which is a direct consequence of the selected permeability law evolution. This probably means that the large size of pores, the inter-pellets pores, do not play a major role in the transient evolution. These large pores probably close quickly and only change the permeability during a short period. Oppositely, the quality of local measures as radial stresses or density is much scattered and less easily reproduced, meaning that probably additional researches are needed.

\section{Acknowledgements}

The authors would like to acknowledge the European project BEACON for its financial support (project receiving funding from the Euratom research and training programme 2014-2018 under grant agreement No 745942

\section{References}

1. C. Dieudonné, Hydromechanical behaviour of compacted bentonite: from micro-scale analysis to macro-scale modelling, (University of Liege, 2016)

2. Y. J. Cui, JRMGE 9, 565-574, (2017)

3. Q. Wang et al., Eng. Geol. 164, 67-76 (2013)

4. A. Molinero Guerra, Experimental and numerical characterizations of the hydro-mechanical behavior of a heterogeneous material: pellet/powder bentonite mixture. (Ecole des Ponts ParisTech, 2019)

5. F. Bernachy and W. Guillot, Bentonite mechanical evolution - Experimental work for the support of model development and validation, D.4.1/2, (BEACON project, 2019)

6. M. Van Geet, G. Volckaert, S. Roels, Appl. Clay Sci. 29, 73-87 (2005)

7. A. Molinero Guerra et al., Appl. Clay Sci. 135, 164-169 (2017)

8. C. Imbert and M. Villar, V. Appl. Clay Sci. 32, 197-209 (2006)

9. J. Talandier, Specifications for BEACON WP5: testing, verification and validation of models step 1Verification cases, D5.1.1. (BEACON project, 2018)

10. E. E. Alonso, A. Gens, A. Josa, Geotechnique 40, 405-430 (1990)

11. A. Dueck and U. Nilsson, Thermo-HydroMechanical properties of MX-80 - Results from advanced laboratory tests, TR-10-55, (SKB, 2010)

12. A. C. Dieudonné et al., A water retention model for compacted clayey soils, Third International Symposium on Computational Geomechanics, (Krakow, Polland, 2013)

13. E. Romero, Eng. Geol. 165, 3-19 (2013)

14. A. Seiphoori, A. Ferrari, L. Laloui, Géotechnique 64, 721-734 (2014) 